\title{
RANCANGAN APLIKASI PEMINJAMAN DAN PEMELIHARAAN BUS SEKOLAH DI UNIT PENGELOLA ANGKUTAN SEKOLAH
}

\author{
Irham Khoerul Anam¹, Nur Alam Arifin², Tria Hadi Kusmanto ${ }^{3}$ \\ 1,2,3 Teknik Informatika,Fakultas Teknik dan Ilmu Komputer, Universitas Indraprasta PGRI Jakarta \\ Jalan Raya Tengah No 80, Kelurahan Gedong, Pasar Rebo, Jakarta Timur \\ 1khoerul.irkham12@gmail.com, 2alamarifin@gmail.com,3triahadi226@gmail.com
}

\begin{abstract}
ABSTRAK
Permasalahan yang terdapat pada Unit Pengelola Angkutan Sekolah adalah terjadinya kehilangan berkas pada saat pelaporan bulanan kepada pimpinan diakibatkan human error serta kendala yang timbul adalah pada saat proses pendataan dan sering terjadi kesalahan pencatatan, dan pelaporan. Tujuan merancang suatu sistem informasi peminjaman dan pemeliharaan bus sekolah ini dengan tujuan untuk memudahkan admin dalam memproses pengolahan data yang ada saat ini. Perangkat aplikasi yang telah dibuat dengan bahasa pemrograman Java NetBeans 8.0.2 dan penyimpanan data pada database MySQL dapat memberikan kelancaran dalam proses menginput dan penyimpanan data-data serta laporan-laporan yang diberikan kepada Pimpinan perusahaan. Dengan menggunakan metode pengembangan sistem yaitu Waterfall dalam penelitian ini adalah dengan tahapan-tahapan seperti rekayasa sistem, analisis, desain, coding, testing, dan maintenance. Hasil dari penelitian ini menciptakan suatu sistem informasi peminjaman dan pemeliharaan bus sekolah yang dapat memudahkan pihak perusahaan dalam proses pendataan data karyawan, data peminjaman bus serta proses pendataan data pemeliharaan bus yang lebih baik dan akurat.
\end{abstract}

Kata Kunci: Aplikasi, Peminjaman, Pemeliharaan, Bus, Desktop

\begin{abstract}
The problems found in the School Transportation Management Unit are the occurrence of file loss during monthly reporting to the leadership due to human error and the obstacles that arise during the data collection process and frequent recording and reporting errors. The purpose of designing an information system for borrowing and maintaining school buses is to make it easier for admins to process the current data processing. Application devices that have been created with the Java NetBeans 8.0.2 programming language and data storage in the MySQL database can provide smoothness in the process of inputting and storing data and reports given to company leaders. By using the system development method, namely Waterfall, in this research, the stages are systems engineering, analysis, design, coding, testing, and maintenance. The results of this study create an information system for borrowing and maintaining school buses that can facilitate the company in the process of collecting employee data, bus borrowing data and the process of collecting data for bus maintenance data that is better and more accurate.
\end{abstract}

Key Word: Application, Borrow, Maintenance, Bus, Desktop

\section{PENDAHULUAN}

Perkembangan teknologi informasi pada jaman seperti sekarang ini berkembang dengan pesat kemajuanya. Kehadiran komputer ditengahtengah aktivitas bagi kalangan bisnis, merupakan salah satu alternatif dalam mengatasi permasalahan-permasalahan yang makin sering terjadi dan untuk meningkatkan efektifitas serta efisiensi (Shadiq, Safei, Wahyudin, \& Loly, 2021).

Pada saat ini sistem aplikasi sangat berpengaruh disegala bidang kehidupan baik dibidang politik, pendidikan, maupun ekonomi, khususnya dibidang peminjaman dan pemeliharaan bus sekolah gratis di Unit Pengelola Angkutan Sekolah DKI Jakarta (Trenggono, 2014). Tetapi dalam kenyataan masih banyak ditemukan perusahaan yang masih menerapkan metode manual dan sistem manajemen dan administrasinya. Sehingga kesiapan untuk melayani kebutuhan para karyawan belum maksimal dan menyulitkan dalam pengontrolan data dan pembuatan laporan kepada pimpinan. Untuk menghasilkan mutu informasi yang baik, serta secara akurat dalam memperbaiki kesalahan- 
kesalahan yang sedang terjadi dalam pekerjaan dengan sistem yang manual, maka perusahaan membutuhkan suatu sistem komputer yang dapat membantu kinerja serta mengefesiensikan berbagai sumber daya seperti waktu dan semua sumber daya (Pratama, Arifin, Citra, \& Dwi, 2020).

Unit Pengelola Angkutan Sekolah DKI Jakarta dibawah kepemimpinan Ir. Moh. Insaf, M.T. kini telah berkembang pesat dari jumlah rute dan zona pelayanan, jumlah penumpang yang diangkut, jumlah kendaraan yang beroperasi dan kebutuhan jumlah awak bus (Kurniawan \& Irsyadi, 2021). Unit Pengelola Angkutan Sekolah DKI Jakarta yang beralamat di Jl. Raya Pd. Gede No.30, RT.1/RW.2, Dukuh, Kec. Ciracas, Kota Jakarta Timur, Daerah Khusus Ibukota Jakarta 13830. Menurut Kepala Unit Pengelola Angkutan Sekolah saat ini proses peminjaman dan pemeliharaan bus sekolah gratis dalam pencatatannya masih manual dengan media kertas dan sering terjadi human error, pelaporan kepada pimpinan pun terkadang sering mengalami keterlambatan. Dengan kondisi seperti ini dibutuhkan sistem informasi dalam mengatasi permasalahan yang ada didalam perusahaan (Puspaningrum \& Sudarmilah, 2020).

Dengan permasalahan tersebut, perlu ada nya suatu sistem yang terkomputerisasi dalam penyelesaiannya. Sistem adalah sekelompok unsur yang erat hubungannya satu dengan yang lain, yang berfungsi bersama-sama untuk mencapai tujuan (Sutabri, 2012). Sistem merupakan suatu kumpulan dari komponenkomponen yang membentuk satu kesatuan (Tyoso, 2016). Pembangunan sistem adalah sekumpulan aktivitas yang menggambarkan secara rinci bagaimana sistem akan berjalan. Hal itu bertujuan untuk menghasilkan produk perangkat lunak yang sesuai dengan kebutuhan user (Satzinger, J. W., Jackson, R. B., Burd, n.d.).

Diharapkan dengan adanya suatu sistem informasi dapat menangani permasalahan yang ada di perusahaan tersebut. Sistem adalah setiap sesuatu terdiri dari obyek-obyek, atau unsur-unsur, atau komponen-komponen yang bertata kaitan dan bertata hubungan satu sama lain, sedemikian rupa sehingga unsur-unsur tersebut merupakan satu kesatuan pemrosesan atau pengolahan yang tertentu. (Prasojo, 2011)

Berdasarkan hasil penelitian yang terdahulu oleh (Ismiyati, Firdaus, \& Arubusman, 2017), bertujuan menganalisis sistem manajemen operasional pemeliharaan Bus Transjakarta dalam meningkatkan kebutuhan rasa aman dan nyaman bagi masyarakat pengguna. Penelitian menggunakan metode deskriptif-kualitatif. Hasil penelitian:1) pelaksanaan program busway yang telah dan sedang dilaksanakan oleh Pemerintah Daerah Khusus Ibukota (DKI) Jakarta melalui Dinas Perhubungan dan Badan Pengelola (BP) Transjakarta sebagian besar telah sesuai yang diharapkan, antara lain dalam bidang sarana dan prasarana seperti sistem tiketing, halte, sarana bis, SDM dan publikasi; 2) kinerja pelaksanaan program busway, secara umum telah menunjukkan tingkat kepuasan penggunanya. Busway dianggap sebagai sarana angkutan umum alternatif yang dapat memberikan rasa aman, nyaman dan ketepatan waktu tempuh, yang selama ini hal tersebut tidak dapat dilakukan oleh angkutan umum yang ada; 3) evaluasi pelaksanaan program busway selama satu tahun terakhir telah menunjukkan hasil yang cukup menggembirakan. Busway telah dapat menyerap penumpang sebanyak 17,4 juta orang dan kemampuan untuk menarik pengguna kendaraan pribadi mencapai 7,6 persen lebih besar dari rata-rata di dunia yang mencapai 4 sampai 5 persen. Dalam mengurangi masalah kemacetan program ini belum menunjukkan perubahan yang signifikan. Program ini juga telah menghasilkan pendapatan bagi kas daerah (tahun 2015) sebesar Rp. 42,7 miliar dan perubahan perilaku masyarakat.

Aplikasi yang dirancang ini dapat memudahkan pekerjaan Admin dalam melaksanakan proses penginputan data, serta pencarian data lebih cepat dan efektif serta pembuatan laporan dan dapat memudahkan perusahaan dalam pendataan data peminjaman dan pemeliharaan bus sekolah sekolah yang lebih baik dan akurat lagi.

\section{METODE PENELITIAN}

Peneliti menggunakan metode Research and Development dalam penyelesaian penelitian ini. (Sugiyono, 2016). Dalam pelaksanaan R\&D, ada beberapa metode yang digunakan yaitu metode 
deskriptif, evaluatif dan eksperimental. Metode penelitian deskriptif digunakan dalam penelitian awal untuk menghimpun data tentang kondisi yang ada yaitu penulis membutuhkan data-data yang dapat menunjang tercipta nya suatu sistem informasi peminjaman dan pemeliharaan mobil seperti data mobil, data karyawan, data petugas, data peminjaman mobil dan data pemeliharaan mobil terdahulu yang masih tersimpan secara manual didalam buku besar.

Metode evaluatif digunakan untuk mengevaluasi proses ujicoba pengembangan suatu produk, dalam proses ini penulis melakukan ujicoba terhadap suatu sistem yang telah dirancang agar tidak ada terjadi kesalahan dalam proses penginputan data serta pelaporan bulanan kepada pimpinan. Dan metode eksperimen digunakan untuk menguji keampuhan dari produk yang dihasilkan, dalam proses yang terakhir ini perlu dilakukan pengujian akhir yang diharapkan bahwa sistem yang dirancang oleh penulis dapat berjalan dengan baik dan sesuai dengan kebutuhan dan terfokus pada proses peminjaman dan pemeliharaan bus sekolah gratis di Unit Pengelola Angkutan Sekolah DKI Jakarta (Putra, 2011).

Adapun jadual penelitian yang dilakukan sebagai berikut: Pada bulan ke-1 dilakukan proses analisis kebutuhan sistem, mendapatkan data-data yang dibutuhkan untuk perancangan sistem. Kemudian bulan ke-2 dilakukan proses observasi, mempelajari proses-proses pada Unit Pengelola Angkutan Sekolah DKI Jakarta dengan memahami proses pendataan bus sekolah, peminjaman dan pengembalian bus sekolah dan pembuatan laporan. Bulan ke-3 dilakukan proses implementasi sistem dan pengujian sistem tersebut, sistem aplikasi yang sesuai dengan kebutuhan perusahaan sehingga dapat menghasilkan kinerja perusahaan menjadi lebih baik dan efektif.

\section{HASIL DAN PEMBAHASAN}

\section{Alternatif Penyelesaian Masalah}

Alternatif pemecahan masalah yang akan penulis lakukan untuk mempermudah proses kerja pada Unit Pengelola Angkutan Sekolah DKI Jakarta, yaitu:

1. Merancang sistem aplikasi yang lebih baik untuk dapat membantu kinerja bagian admin dalam mengelola setiap proses yang terjadi pada perusahaan serta membantu dalam mengolah data-data perusahaan.

2. Merancang sistem aplikasi peminjaman dan pemeliharaan bus sekolah gratis dengan sistem terkomputerisasi. Jadi, setiap peminjaman bus yang terjadi, seperti proses peminjaman, pengembalian, dan data laporan akan disimpan ke dalam database. Kemudian laporan yang dibutuhkan akan ditampilkan secara otomatis tanpa harus menggunakan cara manual lagi.

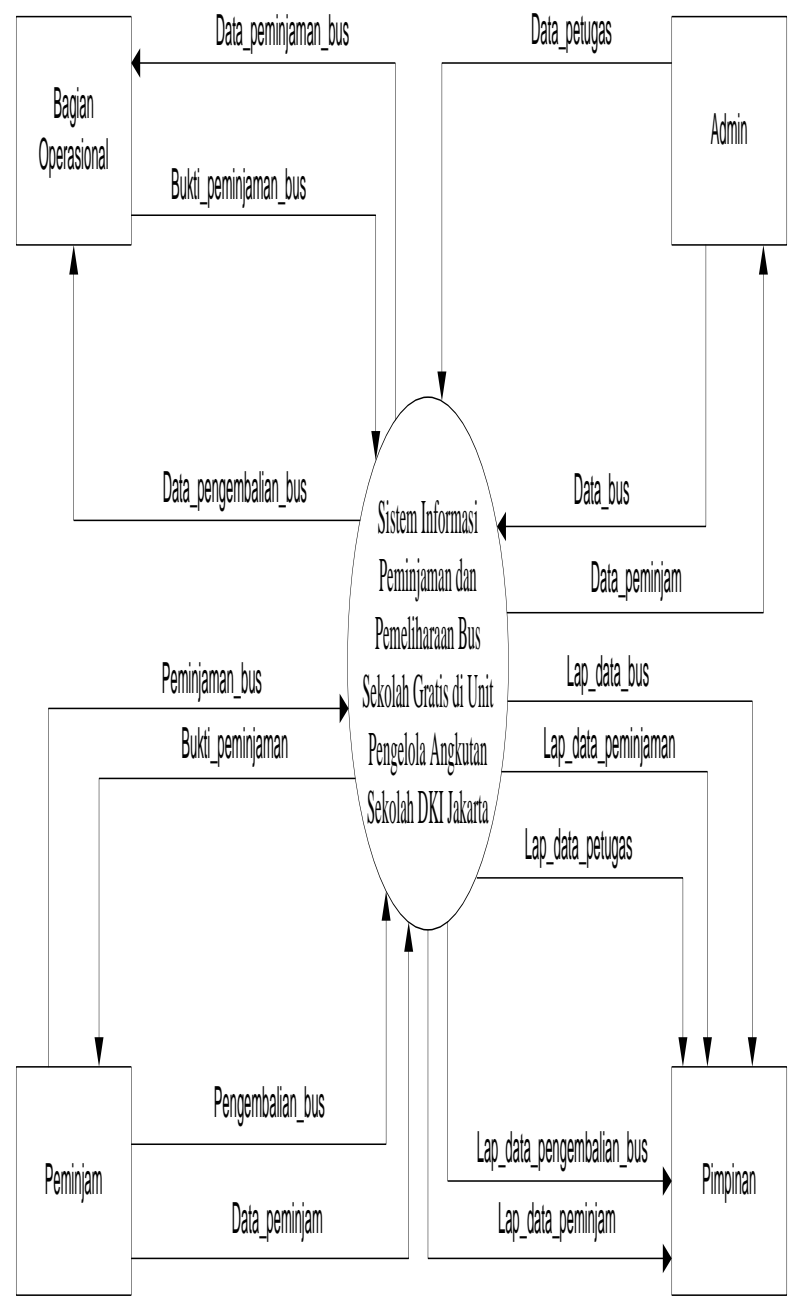

Gambar 1. Diagram Konteks 


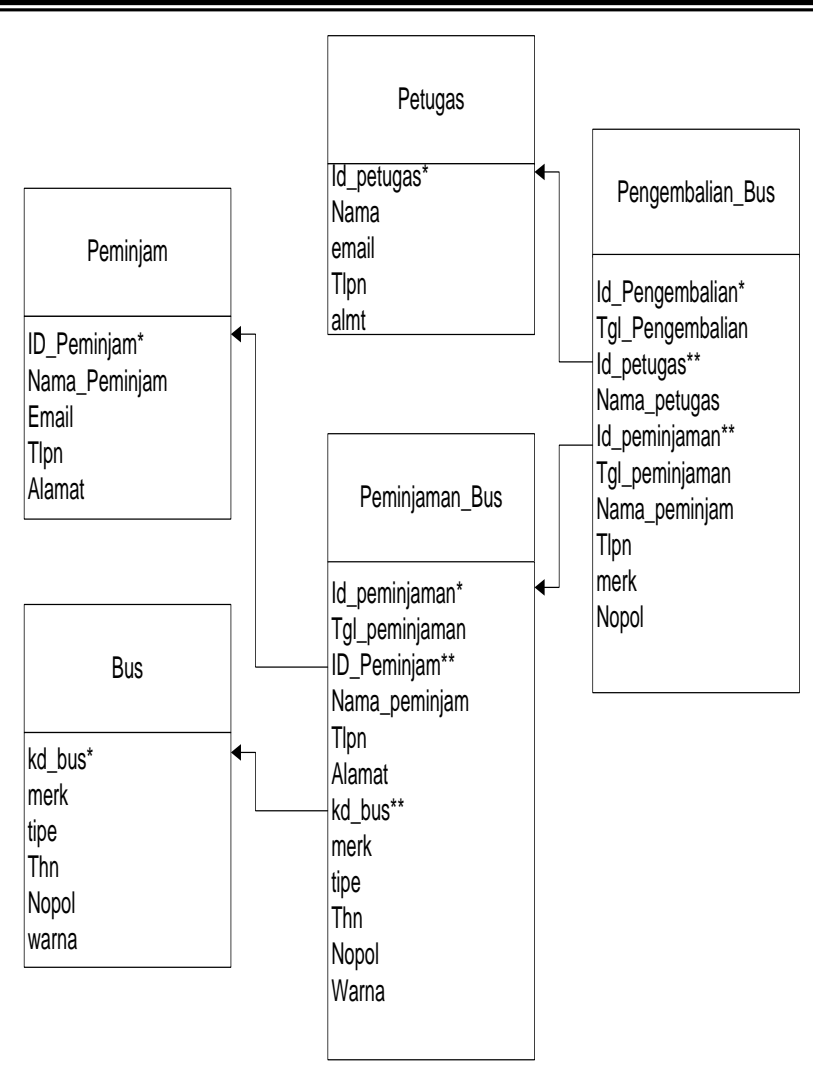

Gambar 2. Normalisasi

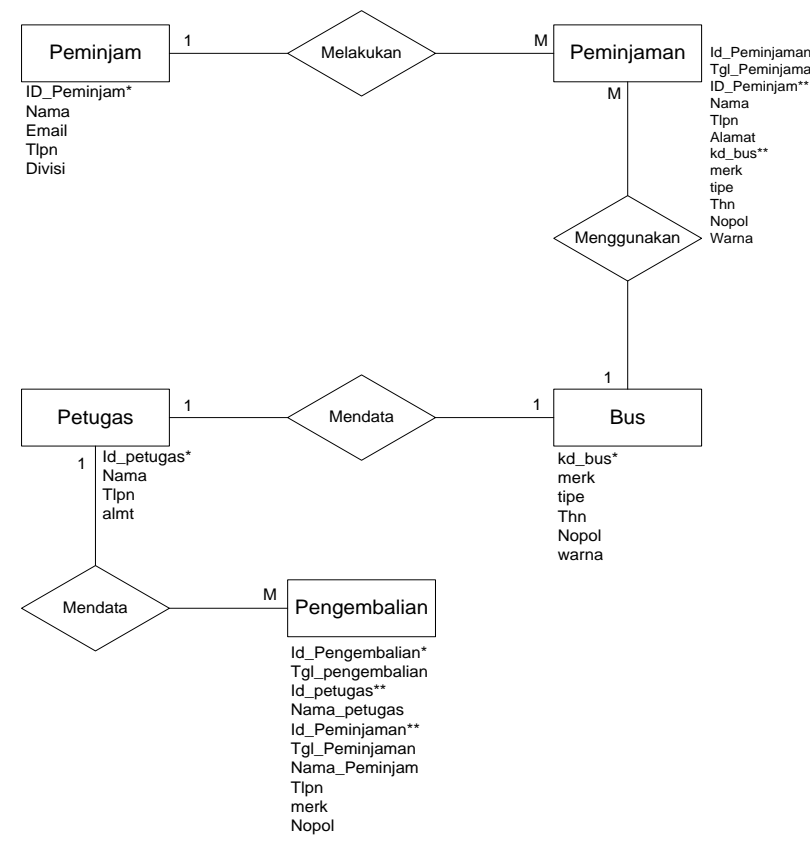

Gambar 3. ERD (Entity Relationship Diagram)
Berikut adalah tampilan layar dan hasil pengujian pada software program yang telah di buat dengan bahasa pemrograman Java.

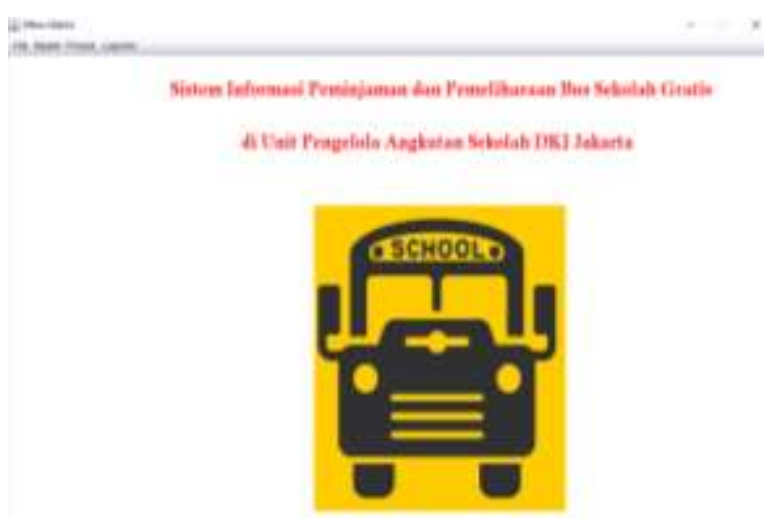

Gambar 4. Form Menu Utama

Layar di atas menampilkan tampilan menu Tampilan Sistem Informasi Peminjaman dan Pemeliharaan Bus Sekolah Gratis di Unit Pengelola Angkutan Sekolah DKI Jakarta. Pada layar utama tersedia menubar yang terdiri dari menu Akses yang digunakan pada saat pengguna ingin login atau exit dari aplikasi, menu Berkas yang digunakan untuk memasukkan data yang berkaitan dengan data petugas, data karyawan, data bus, data peminjaman bus, dan data pengembalian bus. Kemudian menu laporan untuk mencetak semua laporan data petugas, data karyawan, data bus, data peminjaman bus, data pengembalian bus dan surat booking bus serta bukti pengembalian bus.

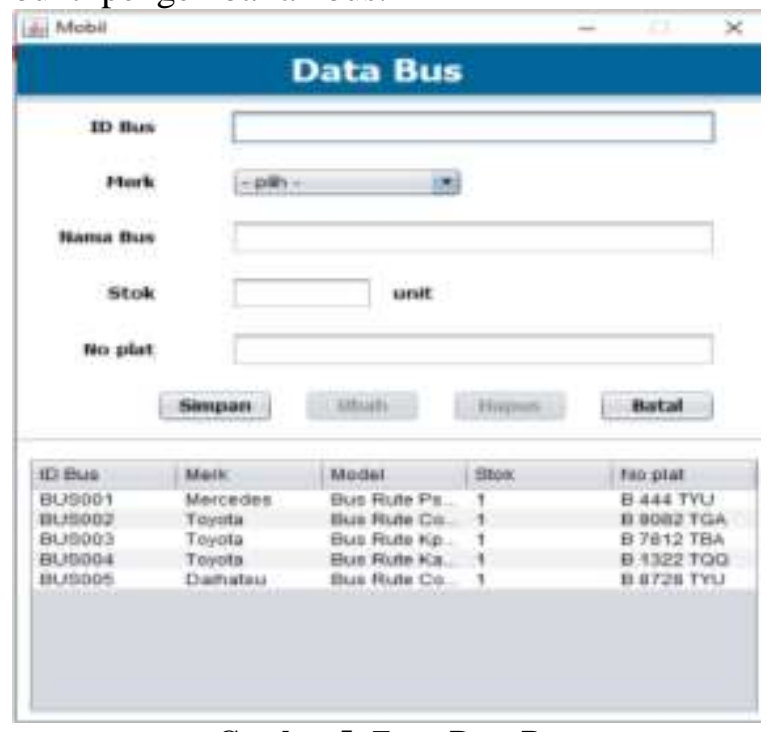

Gambar 5. Form Data Bus 
Layar di atas menampilkan tampilan form data bus. Pada layar form data bus untuk menginput data bus yang terdiri dari ID Bus, Merk, Nama Bus, Stok, dan No Plat.

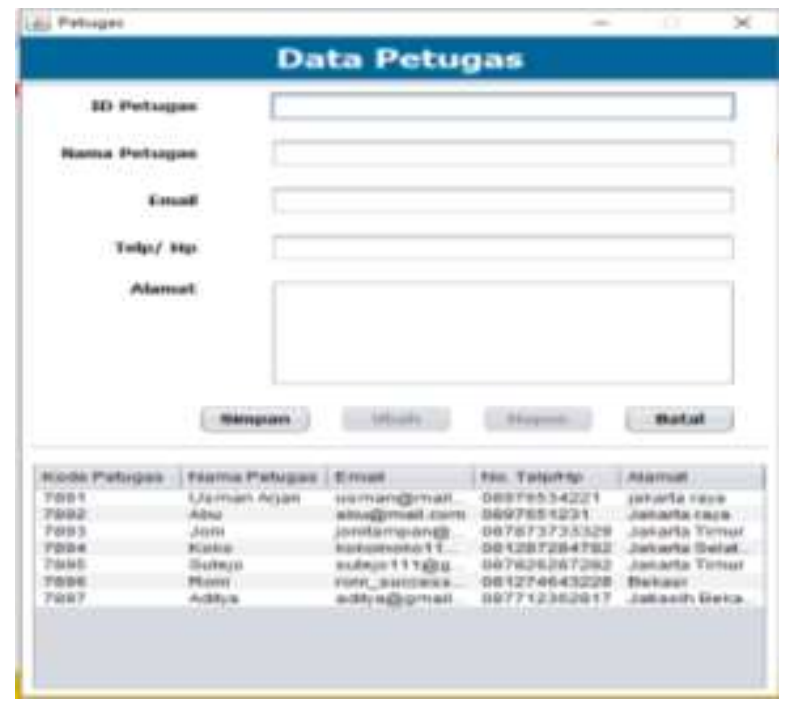

Gambar 6. Form Data Petugas

Layar di atas menampilkan tampilan form data petugas. Pada layar form data petugas untuk menginput data petugas yang terdiri dari ID Petugas, Nama Petugas, Email, Telp/HP dan Alamat.

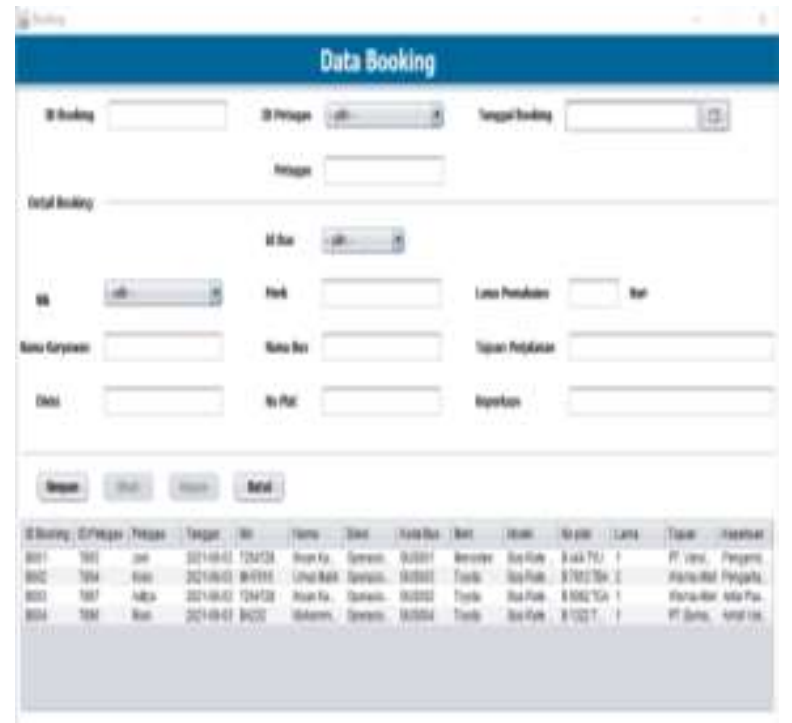

Gambar 7. Data Form Data Booking Bus

Layar di atas menampilkan tampilan form data booking bus. Pada layar form data booking bus untuk menginput data booking bus yang terdiri dari ID Booking, ID Petugas, Nama Petugas, Tanggal Booking, NIK, Nama Karyawan, Divisi,
ID Bus, Merk, Nama Bus, No Polisi, Lama Pemakaian, Tujuan Perjalanan dan Keperluan.

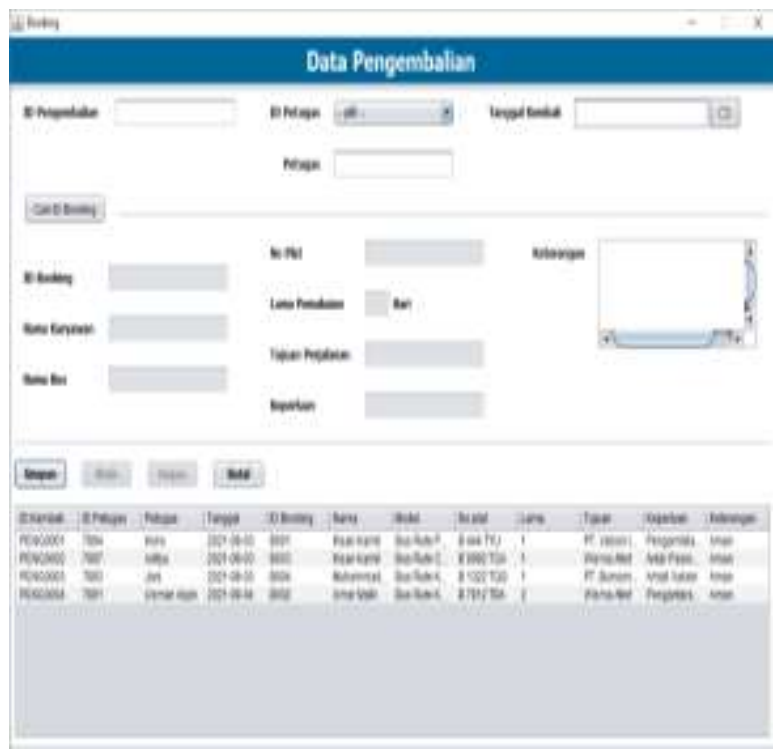

Gambar 8. Data Form Pengembalian Bus

Layar di atas menampilkan tampilan form data pengembalian bus. Pada layar form data pengembalian bus untuk menginput data pengembalian bus yang terdiri dari ID Pengembalian, ID Petugas, Nama Petugas, Tgl Pengembalian Bus, ID Booking, Nama Karyawan, Nama Bus, No Polisi, Lama Pemakaian, Tujuan Perjalanan, Keperluan dan Keterangan.

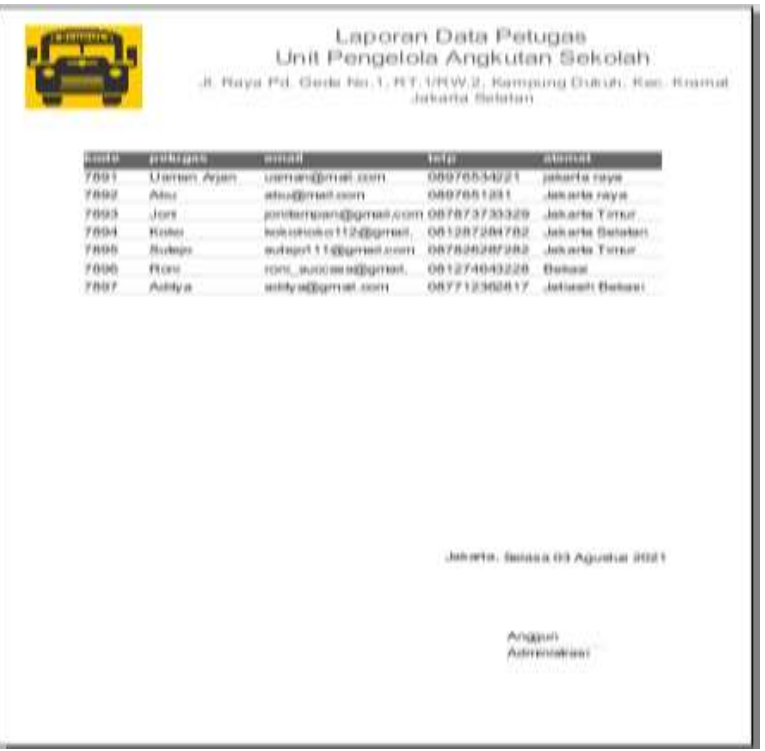

Gambar 9. Laporan Data Petugas

Layar di atas menampilkan tampilan form laporan data petugas. Pada layar form laporan data petugas 
terdapat informasi data petugas yang terdiri dari ID Petugas, Nama Petugas, Email, No Telp/HP dan Alamat.

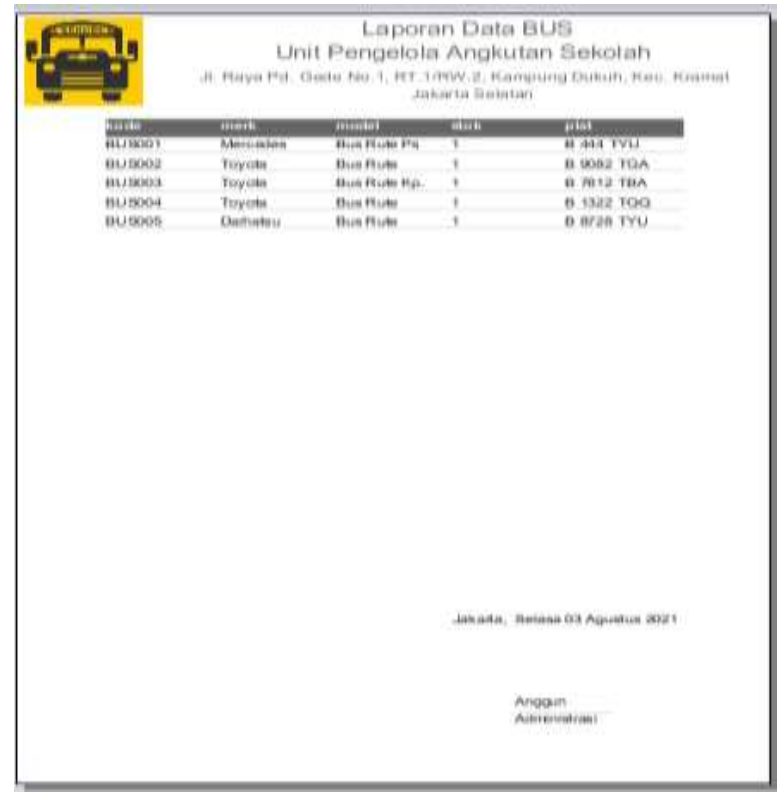

Gambar 10. Laporan Data Bus

Layar di atas menampilkan tampilan form laporan data bus. Pada layar form laporan data bus terdapat informasi data bus yang terdiri dari ID Bus, Merk, Nama Bus, Stok dan No Plat.

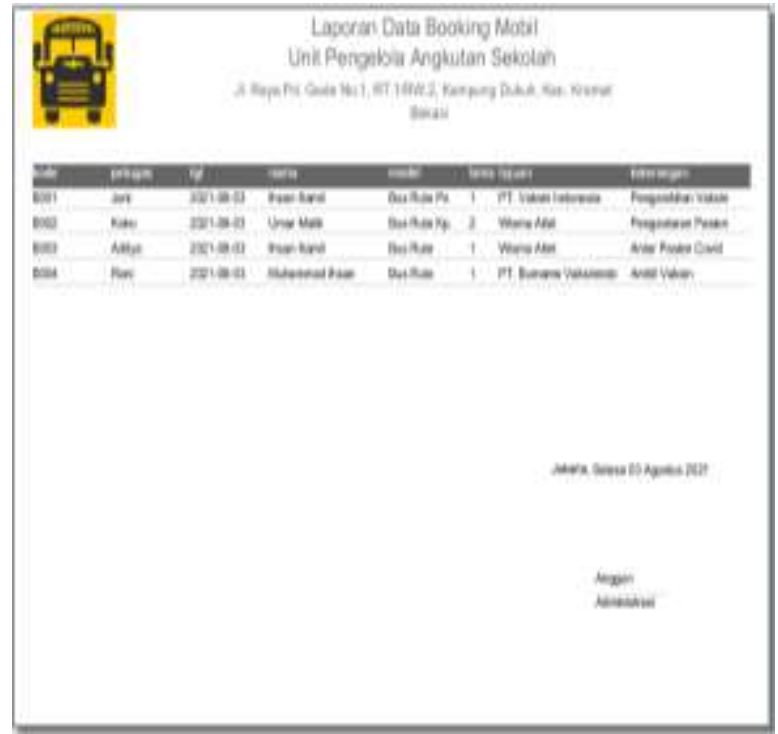

Gambar 11. Laporan Data Peminjaman Bus

Layar di atas menampilkan tampilan form laporan data peminjaman bus. Pada layar form laporan data peminjaman bus terdapat informasi data peminjaman bus yang terdiri dari ID Peminjaman, Nama Petugas, Tgl Peminjaman, Nama Petugas, Nama Bus, Lama Peminjaman, Tujuan Perjalanan dan Keterangan.

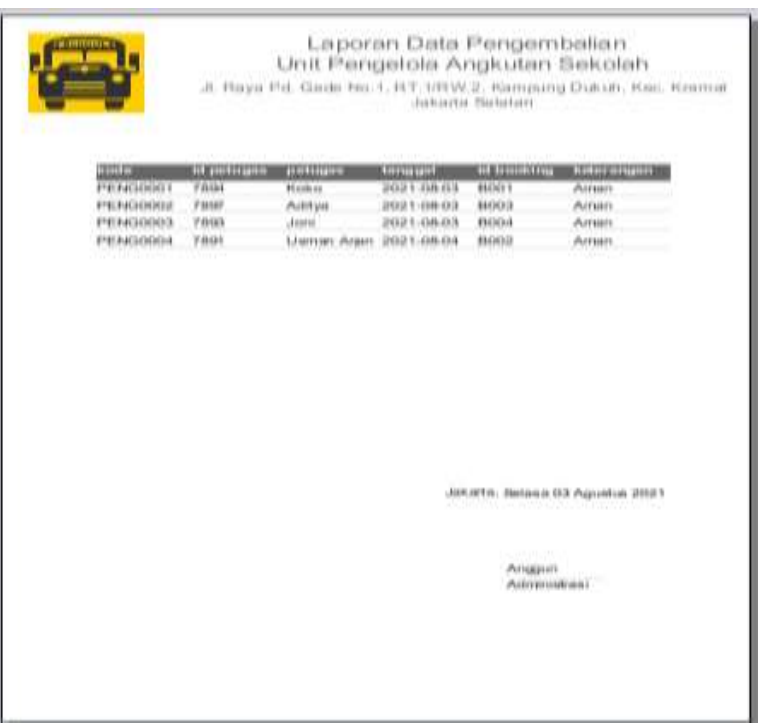

Gambar 12. Laporan Data Pengembalian Bus

Layar di atas menampilkan tampilan form laporan data pengembalian bus. Pada layar form laporan data pengembalian bus terdapat informasi data pengembalian bus yang terdiri dari ID Pengembalian Bus, ID Petugas, Nama Petugas, ID Peminjaman, Tgl Pengembalian dan Keterangan.

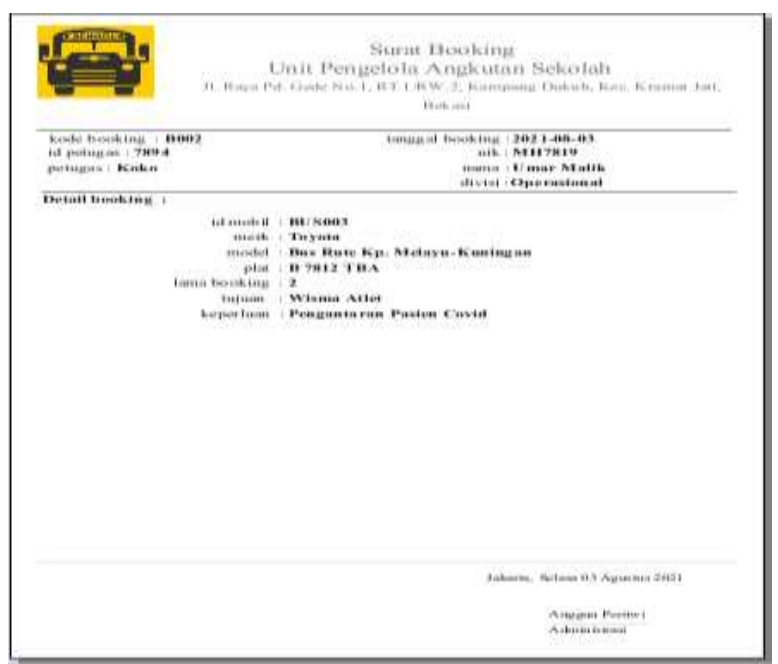

Gambar 13. Surat Booking Bus

Layar di atas menampilkan tampilan surat booking bus. Pada tampilan surat booking bus terdapat informasi seperti Kode Bus, Tgl Booking, ID Petugas, Nama Petugas, NIK, Nama Karyawan, 
Divisi, ID Bus, Merk, Nama Bus, No Plat, Lama Booking, Tujuan Perjalanan dan Keperluan.

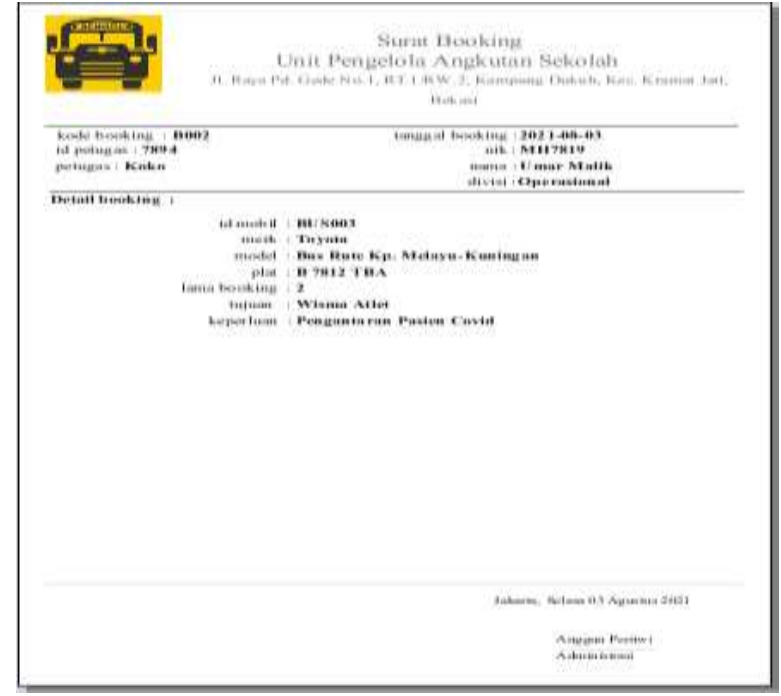

Gambar 14. Bukti Pengembalian Bus

Layar di atas menampilkan tampilan bukti pengembalian bus. Pada tampilan bukti pengembalian bus terdapat informasi seperti Kode Pengembalian, Tanggal Kembali, NIK, Nama Karyawan dan Model Bus.

\section{SIMPULAN DAN SARAN}

Aplikasi peminjaman dan pemeliharaan bus sekolah gratis di Unit Pengelola Angkutan Sekolah DKI Jakarta menggantikan sistem lama, admin tidak perlu melakukan penginputan data secara manual lagi, karena sistem aplikasi ini menyediakan form penginputan. Selain itu, sistem aplikasi peminjaman bus tersebut juga sangat membantu admin dalam membuat laporan, karena sistem aplikasi ini dapat menghasilkan laporan harian maupun laporan bulanan yang dapat langsung dicetak.

Disarankan perusahaan menggunakan sistem yang dirancang ini, agar masalah-masalah yang ada sekarang pada sistem peminjaman dan pemeliharaan bus dapat diatasi dengan baik dan perlu dikembangkan lagi dimasa mendatang sesuai dengan kemajuan teknologi.

Dan bagi peneli selanjutnya, hasil penelitian ini bisa digunakan sebagai bahan perbandingan adn referensi untuk penelitian, dan sebagai bahan pertimbangan untuk lebih memperdalam penelitian selanjutnya sehinggan proses peminjaman dan pemeliharaan bus agar bisa lebih efektif dan real-time.

\section{DAFTAR PUSTAKA}

Ismiyati, I., Firdaus, M., \& Arubusman, D. A. (2017). Manajemen Pemeliharaan Bus Transjakarta Dalam Mencapai Standar Pelayanan Minimum. Jurnal Manajemen Transportasi Dan Logistik, 3(2), 185. https://doi.org/10.25292/j.mtl.v3i2.92

Kurniawan, D. W., \& Irsyadi, F. Y. (2021). Perancangan dan Pembuatan Aplikasi Manajemen Peminjaman Kendaraan Berbasis Web Dengan Framework Codeigniter. 21(01).

Prasojo, M. (2011). Pengantar Sistem Informasi Manajemen . bandung: CV. Remadja Karya.

Pratama, R. S., Arifin, A. K., Citra, A., \& Dwi, D. (2020). Sistem Aplikasi Peminjaman Kendaraan Bermotor PT Trans Mitra Nusantara. $\quad 3(2), \quad 69-75$. https://doi.org/10.32493/jtsi.v3i2.3720

Puspaningrum, A., \& Sudarmilah, E. (2020). Sistem Informasi Manajemen Peminjaman (Studi Kasus: Pengelolaan Aset Dan Tata Ruang Taman Budaya Jawa Tengah). Technologia: Jurnal Ilmiah, 11(1), 37. https://doi.org/10.31602/tji.v11i1.2699

Putra, N. (2011). Research and Development, Penelitian dan Pengembangan: Suatu Pengantar. Jakarta: PT Raja Grafindo Persada.

Satzinger, J. W., Jackson, R. B., Burd, S. D. (n.d.). System Analysis and Design in A Changing World. USA: Cengage Learning.

Shadiq, J., Safei, A., Wahyudin, R., \& Loly, R. (2021). Pengujian Aplikasi Peminjaman Kendaraan Operasional Kantor Menggunakan BlackBox Testing. 5(2), 97-110.

Sugiyono. (2016). Metode Penelitian Kuantitatif, Kualitatif dan $R \& D$. Bandung: PT Alfabet.

Sutabri, T. (2012). Analisis Sistem Informasi. Yogyakarta: Andi.

Trenggono, D. H. (2014). Perancangan Sistem Peminjaman Berbasis Web Sebagai Media Layanan di Studio Multimedia SMK 2 Sewon. Skripsi, 10-17.

Tyoso, J. S. P. (2016). Sistem Informasi Manajemen. Yogyakarta: DeePublish. 